\title{
La transformación de la Sociedad Civil: un proyecto en clave deliberativa
}

\author{
Civil society transformation: \\ A deliberative-based project
}

\author{
PEDRO JESÚS PÉREZ ZAFRILLA \\ Universidad de Valencia
}

Recibido: 03-03-2008 Aprobado definitivamente: 19-11-2008

\begin{abstract}
RESUMEN
En las últimas décadas el concepto de sociedad civil ha sufrido una importante transformación en el marco de la filosofía política, a raíz de su tratamiento por parte de los autores de la democracia deliberativa. Si bien una parte de los proponentes de esta teoría de la democracia asimilaron el esquema tradicional que reducía la sociedad civil a la esfera privada, otros han sabido ir más allá y la han situado en un lugar privilegiado dentro de la esfera pública. De esta manera ha sido posible reforzar el papel de la sociedad civil en nuestras sociedades, gracias así a las propuestas de la democracia deliberativa.

PALABRAS CLAVE

SOCIEDAD CIVIL, DEMOCRACIA DELIBERATIVA, CULTURA SOCIAL, ESFERA

PÚBLICA

ABSTRACT

In the last decades the concept of civil society suffered an important transformation in the political philosophy, because of its treatment by the writers of deliberative democracy. Although one part of the authors of this theory of democracy assimilated the traditional scheme which reduced the civil society to the private sphere, others moved forward and situated it in a privileged place within the public sphere. Thus, it has been possible to strengthen the role of civil society role within our societies, due to the proposals of deliberative democracy.
\end{abstract}

KEY WORDS

CIVIL SOCIETY, DELIBERATIVE DEMOCRACY, SOCIAL CULTURE, PUBLIC SPHERE

(C) Contrastes. Revista Internacional de Filosofía, vol. XIV (2009), pp. 199-215. ISSN: 1136-4076 Licenciatura de Filosofía, Universidad de Málaga, Facultad de Filosofía y Letras Campus de Teatinos, E-29071 Málaga (España) 


\section{INTRODUCCIÓN}

La Democracia Deliberativa, DeSDe su aParición Con Barber a comienzos de la década de los ochenta del siglo pasado, constituye una de las propuestas más innovadoras de la teoría de la democracia. Entre los elementos característicos de esa teoría destaca sobretodo su crítica al sistema liberal imperante hasta la fecha. Incluso podría decirse que la democracia deliberativa surgió por contraposición a los métodos empleados por el modelo liberal. ${ }^{1}$ Frente a la agregación de preferencias, se apostará por la transformación de las mismas, ${ }^{2}$ frente al sistema representativo, se propondrá -en cierta medida- una participación más directa de los ciudadanos en el foro público; ${ }^{3}$ frente al sujeto apático liberal, se aspirará a uno razonable y comprometido con la sociedad. ${ }^{4}$ Pero, fundamentalmente, frente a la participación basada en el voto secreto, los autores de la democracia deliberativa articularán otro modelo fundado en la argumentación y la deliberación moral entre los individuos comprometidos con el bien común. ${ }^{5}$

Ciertamente, esta oposición al sistema liberal es un elemento clave para entender la aparición y desarrollo de esta teoría de la democracia. Sin embargo, no sería adecuado quedarnos con esta vaga caracterización de la democracia deliberativa como una teoría unilineal que pretenda meramente la reforma del liberalismo en pos de la instauración de un sistema participativo de democracia. Más bien hemos de reconocer que la democracia deliberativa «se dice de muchas maneras», siendo varios los enfoques que distintos autores han desarrollado en torno a esta teoría. Así podemos encontrar una corriente republicana, representada por Benjamin Barber; otra liberal, con Rawls a la cabeza y que ha sido continuada por seguidores suyos como Amy Gutmann, Dennis Thompson, Henry Richardson o David Crocker; también desde la ética discursiva se han sumado

1 J. Bohman, «Survey article: The coming of age of deliberative democracy», Journal of Political Philosophy, 6, (1998), pp. 400-425.

2 J. Mansbridge, «A deliberative theory of interest representation», en M. P. Petracca (ed.), The politics of interest. Oxford: Westview Press, 1992, p. 37; E. J. Leib. «Can direct democracy be made deliberative?», Buffalo Law Review, 54, (2007), pp. 912-5.

3 B. Barber, Democracia fuerte. Córdoba: Almazara, 2004, p. 330.

4 S. Benhabib, «Toward a deliberative model of democratic legitimacy», en Seyla Benhabib (ed.), Democracy and difference. Princenton: Princenton University Press, 1996, p. 71; cf. B. Manin. «On legitimacy and political deliberation», Political Theory, 15, (1987), pp. 349-50.

5 G. Gaus, «Reason, justification and consensus: why democracy can't have it all», en James Bohman y William Rehg (eds). Deliberative democracy. Essays on reason and politics. Cambridge: The MIT Pres, 1997, p. 209; cf. H. Richardson, Democratic autonomy Public reasoning about the ends of policy. Oxford: Oxford University Press, 2002, p. 149. 
con sus propuestas a este nuevo modelo de democracia, como hace Habermas con su idea de «política deliberativa» desarrollada en Facticidad y validez y otros escritos posteriores, y seguidores suyos como Bohman o Benhabib.

Esta heterogeneidad de planteamientos dentro de la democracia deliberativa se pone precisamente de manifiesto si atendemos a la concepción que los distintos autores desarrollan de la sociedad civil. De hecho, es a la luz de los desarrollos de este concepto por parte de los autores de la democracia deliberativa como puede trazarse la línea de evolución que este concepto ha tenido en la actualidad.

La idea de sociedad civil es un concepto con una larga tradición en la época moderna. ${ }^{6}$ Este concepto, desde sus orígenes, se empleó en el contexto de una distinción heredada de la Edad Media entre el ámbito político del Estado y aquel propio del pueblo. En este sentido se hablaba del dominium de los soberanos, que hacía referencia al poder político, frente a la societas, el pueblo. ${ }^{7}$ Posteriormente, la distinción entre la esfera política y la civil se traducirá en otra entre el ámbito público y el privado. El público es propiamente el político, identificado con la acción coactiva del Estado, mientras que el privado, ocupado por la sociedad civil, será aquel libre del control estatal. Aquí se incluyen todas aquellas actividades y relaciones de los ciudadanos que escapan a la coacción estatal, desde su trabajo o vida familiar, hasta su participación en grupos o colectivos sociales libremente establecidos, como las iglesias, sindicatos, sociedades deportivas, etc...

Esta idea de sociedad civil identificada con las relaciones privadas y voluntarias entre ciudadanos, frente al Estado, se mantendrá en una diversidad de formas a lo largo de la época moderna, desde los teóricos del contrato del siglo XVII, pasando por la Sociedad Civil burguesa teorizada por Hegel, hasta el último tercio del siglo xx. Inicialmente, entre los teóricos del contrato no existe una oposición entre sociedad civil y Estado. La sociedad civil hace referencia a las asociaciones voluntarias creadas para obtener fines diversos, individuales o colectivos. Por su parte, el Estado es en estas primeras interpretaciones el principal garante de esas relaciones sociales. Esto se observa claramente tanto en Hobbes como en Locke, aunque entre ambos existen diferencias: en el Leviatán, Hobbes expone cómo no es posible el orden social sin el Estado. De hecho, ambos elementos se constituyen en un mismo acto y se contraponen ambos al estado de naturaleza, donde no es posible relación comunitaria alguna,

6 Sobre la historia del concepto de sociedad civil puede consultarse la obra de J. Keane, Democracia y sociedad civil. Madrid: Alianza, 1988.

7 A. Cortina (ed.), Diez palabras clave en filosofía política. Estella: Verbo divino, 1998, pp. 356-7. 
al no existir un acuerdo sobre lo justo o injusto. ${ }^{8}$ En cambio para Locke sí que se da una distinción entre la sociedad civil y el Estado. Por un lado, ambos se erigen en momentos diferentes, aunque la función del segundo sigue siendo la preservación de la seguridad en aquélla. Por otro, Locke acentúa el papel del Estado como un instrumento para la protección de las relaciones establecidas en la sociedad civil, frente a la idea hobbesiana del soberano como poseedor de un poder absoluto. ${ }^{9}$

Esta progresiva oposición entre sociedad civil y Estado será puesta de manifiesto por Hegel en su descripción hecha de la sociedad civil burguesa en sus Principios de filosofía del derecho: esta sociedad civil hace referencia a los individuos, clases y grupos cuyas transacciones y relaciones se rigen por los intereses privados y son independientes del Estado. ${ }^{10}$ Se establece así un hiato entre ambos elementos, algo criticado como sabemos, por Hegel, para quien el Estado no será un simple medio para mantener las relaciones privadas de la sociedad civil, sino más bien como un nuevo estadio que permita superar y presentar esa sociedad civil individualista en su justa medida.

Sin embargo, el desarrollo de los hechos parece no haber dado la razón a Hegel: la aparición del Estado mínimo, defendido por los libertarios, en el que la sociedad civil es presentada como un conjunto autosuficiente de relaciones privadas y en el que la intervención estatal se concibe como un ataque a la libertad personal, vuelve a poner de manifiesto la oposición entre Estado y sociedad civil. ${ }^{11}$ En el modelo libertario, el Estado mínimo abandona sus funciones como las labores de bienestar social, las cuales son cubiertas por un conjunto de grupos heroicos que, por decirlo en palabras de Marx, representan «los sentimientos de un mundo sin corazón».

Frente a esta tradicional distinción entre sociedad civil y Estado entendida como una oposición entre los ámbitos público y privado, desarrollada en las diversas formas expuestas, desde el último tercio del siglo pasado distintos autores han intentado articular una forma diferente de entender esa relación entre lo público y lo privado. Su propósito es el de dar cabida dentro del primero al mercado y a las asociaciones espontáneas formadas por los ciudadanos, ya que ambos, el mercado y las asociaciones, tienen una gran influencia en las cuestiones públicas. ${ }^{12}$ Esta inclusión del mercado y las asociaciones voluntarias en el ámbito

8 T. Hobbes, Leviatán. Madrid: Editorial Nacional, 1983, p. 104.

9 J. Locke, Segundo tratado sobre el gobierno civil. Madrid: Tecnos, 2006. Pár.87. cf. T. Hobbes. loc. cit. p. 140.

10 G. W. F. Hegel, Principios de filosofía del derecho. Barcelona: Edhasa, 1999, par. 183-4.

11 B. Barber, Un lugar para todos. Cómo fortalecer la democracia y la sociedad civil. Barcelona: Paidós, 2000, pp. 25-31.

12 M. Walzer, «La idea de sociedad civil. Una vía hacia la reconstrucción social», Debats, 19 (1992), pp. 31-7. 
público tendrá una gran relevancia, pues llevará a redefinir el mismo concepto de sociedad civil. Ahora ya no puede entenderse simplemente como el ámbito privado de los ciudadanos y sus relaciones mutuas no políticas. Se impondrá un concepto de sociedad civil más amplio, que incluirá a esas instituciones sociales que están fuera del control directo del Estado, como el mercado, asociaciones voluntarias y la esfera de la opinión pública. ${ }^{13}$ Pero fundamentalmente, se trata de un concepto de sociedad civil claramente diferenciado del ámbito privado, hasta el punto de dar el salto al ámbito público. Lo público ya no puede entenderse meramente como la esfera de decisión y acción política, o quizá mejor «estatal», sino más bien el ámbito de relación entre el poder político y la sociedad civil, la cual logra su voz a través de la opinión pública.

Esta transformación producida en la actualidad tanto en el concepto de sociedad civil, como en la distinción entre lo público y lo privado, sólo puede entenderse si la ponemos en relación con la forma en que desde la democracia deliberativa se ha desarrollado la idea de sociedad civil. No en vano, han sido ciertos autores de esta teoría de la democracia quienes articularon las coordenadas que impulsaron el cambio producido en el ámbito público. Por ese motivo, en las siguientes páginas deseo exponer cuál ha sido el lugar ocupado por la idea de sociedad civil en el ámbito de la democracia deliberativa. Como mostraré a continuación, la sociedad civil ha sido entendida de diferentes maneras por los distintos autores de la democracia deliberativa. En concreto podemos encontrar tres planteamientos distintos:

En primer lugar tendríamos la propuesta rawlsiana, seguida también en cierta medida por Amy Gutmann y Dennis Thompson. Para todos ellos, siguiendo la línea trazada primeramente entre lo público y lo privado, las asociaciones y colectivos que constituyen la sociedad civil quedan fuera del ámbito público restringido a las instituciones del Estado. ${ }^{14}$ Frente a esta postura podemos encontrar la apoyada por Habermas y Seyla Benhabib. Para ambos, la sociedad civil ejerce de una u otra manera un papel relevante en el foro público: trata de hacer llegar a las instituciones los problemas e intereses de la ciudadanía e intenta influir en la decisión de los gobernantes, pero que en ningún momento participa en el proceso de toma de decisiones, el cual queda limitado al Parlamento. Finalmente, tenemos la propuesta más atrevida, la que apuesta por una mayor descentralización política que haga a la sociedad civil parte integrante del sistema político. En este grupo podemos incluir las teorías de Barber, Joshua Cohen y Joel Rogers, John Dryzek y James Bohman.

13 A. Cortina, loc. cit., p. 361

14 A. Gutmann y D. Thompson, Why deliberative democracy? Princenton: Princenton University Press, 1996, pp. 32-6. 
Esta clasificación nos servirá para ilustrar la tesis fuerte que deseo defender en este trabajo: las distintas formas de entender la sociedad civil dentro de la democracia deliberativa reflejan una transformación que ha sufrido la sociedad civil dentro de esta teoría de la democracia. Se ha pasado de una idea de sociedad civil como simple esfera social sin ninguna relevancia política a un agente plenamente activo en la esfera pública, produciéndose con ello un evidente reforzamiento de la sociedad civil en el marco de las sociedades democráticas. Del mismo modo, este proceso ha ido de la mano de una continua evolución también de la democracia deliberativa.

\section{LA SOCIEDAD CIVIL FUERA DE LA ESFERA PÚBLICA}

Entre los autores de la democracia deliberativa, aquel que de una forma más explícita concibe a la sociedad civil fuera del espacio público es John Rawls. Este autor entiende la sociedad civil como el conjunto de sociedades, clubes, iglesias, equipos y colectivos culturales o profesionales que forman la que denomina «cultura social» o «cultura de la vida cotidiana». Pero resulta significativo que justamente a él oponga la «cultura política». Ésta se compone por las instituciones políticas democráticas, así como los textos en los que se ha plasmado, como las constituciones. ${ }^{15}$ Con ello queda escindido de una forma clara el ámbito público, el político, compartido por todos de una forma individual, como ciudadanos, jueces y políticos, frente al ámbito de las asociaciones y grupos profesionales que quedan así alineados en el ámbito privado.

Esta escisión se refleja también en la forma en que entiende el funcionamiento de los grupos de la sociedad civil. Según Rawls tales grupos se rigen por unos criterios de razonamiento y argumentación que denomina «razones no públicas», frente a la «razón pública», la cual articula la esfera pública en la deliberación y participación política sobre las esencias constitucionales y cuestiones de justicia básica. Con ello, las razones no públicas pertenecientes a la sociedad civil quedan fuera del ámbito público. ${ }^{16}$ Estas razones son no públicas y no privadas en el sentido de que toda razón es por sí misma compartida, nunca individual o privada de una persona. Pero son no públicas al no ser compartidas por todos los ciudadanos, sino sólo por los miembros de cada grupo. Los criterios de corrección de cada asociación no son compartidos por otros ciudadanos. Así por ejemplo, la idea de verdad en una sociedad científica es diferente de la idea de verdad que puede tener una iglesia determinada. Esto hace que las razones no públicas sean inconmensurables entre sí y respecto a la

15 J. Rawls, Liberalismo político. Barcelona: Crítica, 1996, pp. 43-4.

16 Ibid., p. 255. 
razón pública. De esta manera, los miembros de la sociedad civil se mantendrán al margen de la razón pública y la publicidad se restringirá al ámbito político en el que participan los ciudadanos en cuanto tales pero no como representantes de asociaciones. ${ }^{17}$

Por supuesto que en el foro público pueden participar los grupos de la sociedad civil. Él mismo ya lo afirmaba en el Liberalismo político y lo vuelve a ratificar en el artículo «Una revisión de la idea de razón pública». ${ }^{18}$ Pueden participar para exponer sus propuestas, aunque, siempre que se traten cuestiones de justicia básica, deben hacerlo sobre razones que todos puedan compartir, no sobre sus criterios particulares de corrección. Es decir, deben participar sobre la razón pública (esto es, dando razones que todos compartan y apelando a principios y valores compartidos), no sobre sus razones no públicas. De ahí que el participar tales colectivos en el foro público no los convierta en parte del público, porque no lo son.

Sobre este planteamiento nos encontramos a un lado, el ámbito público, compuesto por las instituciones políticas, y al otro las asociaciones y colectivos científicos, religiosos, intelectuales, profesionales... que constituyen la sociedad civil, con sus razones no públicas, sus proyectos e intereses particulares a los que voluntariamente se adhieren los individuos. Como consecuencia de ello se sigue que la sociedad civil nada tiene que ver con el ámbito político y en nada está pensada para influir en él, a diferencia de otros autores que trataremos a continuación. Si una asociación o iglesia quiere influir en el foro público tiene que ser acudiendo a él y sometiéndose a la razón pública al tratar cuestiones de justicia básica.

Pero de esta manera, la cultura social, de la que forma parte la sociedad civil, no será parte del público, lo cual conducirá a un imperialismo de lo político sobre lo civil completamente injustificado. Por ese motivo, la perspectiva de Rawls es errónea ya que esa cultura política tiene como caldo de cultivo la cultura social formada por las tradiciones religiosas que, entre otras, constituyen la cultura social relegada por el autor. ${ }^{19}$ El reto para los autores de la democracia deliberativa será así ampliar la esfera pública para dar cabida en ella junto al sistema político institucional a los grupos que constituyen la sociedad civil. Este es, sin duda, el espíritu que articula el planteamiento de los distintos autores de la democracia deliberativa. Tanto es así que incluso algunos señalan este elemento como el que propiamente diferencia el planteamiento rawlsiano del de la democracia deliberativa. ${ }^{20}$

17 Ibid., p. 250.

18 J. Rawls, «Una revisión de la idea de razón pública», en El derecho de gentes y «Una revisión de la idea de razón pública». Barcelona: Paidós, 2001, pp. 177-8.

19 A. Cortina, Ciudadanos del mundo. Madrid: Alianza, 2003, p. 169; cf. A. Cortina. loc. cit., p. 382.

20 S. Benhabib. loc. cit. , p. 76. 
Pero antes de pasar a ese segundo grupo de autores hemos de hacer referencia a los otros dos pensadores que asientan su teoría sobre los esquemas rawlsianos: Guttman y Thompson. El punto fundamental que nos permite alinear a éstos en el enfoque rawlsiano es que Gutmann y Thompson, al igual que hace Rawls, identifican el ámbito público con lo político, o mejor dicho, con la acción estatal, mientras que la sociedad civil queda relegada a un segundo plano que podemos calificar como un escalón previo a la participación política de los sujetos. La sociedad civil constituye el campo de entrenamiento antes de pasar al que verdaderamente es el foro público, esto es, la participación política. Esto se observa ya en Democracy and disagreement, pero de una forma aún más nítida en su última obra conjunta, Why deliberative democracy? Recordemos cómo en esa primera obra ya distinguían los dos ámbitos en los que debe primar el enfoque deliberativo: por un lado estaba el político, esto es, institucional, y por el otro, los «otros foros deliberativos» en los que participen los ciudadanos para debatir sobre sus problemas. Cuando hablan del foro público parecen aludir simplemente a los foros institucionales, a los cuales les exigen que se sometan a la deliberación moral y no al simple regateo. Por otro lado, ciertamente ambos autores no niegan la relación que existe entre los poderes públicos y los grupos sociales, pero dicha relación se enmarca dentro de la que existe entre los políticos y los ciudadanos y que se rige por el deber de responsabilidad. No otorgan un papel especial a los grupos sociales en la política. Así podemos leer en Democracy and disagreement:

[...] [L]a democracia deliberativa proporciona un proceso continuo. La deliberación continúa a través de pasos, los políticos presentan sus propuestas, los ciudadanos responden, los políticos revisan, los ciudadanos reaccionan y los pasos se repiten. Esto es lo que llamamos la reiteración de la deliberación. ${ }^{21}$

Es decir, el proceso político se desarrolla desde la acción institucional, que debe ser responsable ante los ciudadanos mismos, de acuerdo al deber de responsabilidad. El movimiento es siempre desde ámbito político a la sociedad civil: los políticos hacen un proyecto de ley o una medida determinada y para evaluar su impacto social ponen en funcionamiento unas comisiones que lo estudiarán.

Pero fundamentalmente, el punto clave está en la separación que hacen entre el ámbito institucional y la sociedad civil. Para Gutmann y Thompson, como dije, los grupos de la sociedad civil, convertidos en verdaderos foros de deliberación son en realidad una preparación para participar adecuadamente en la esfera política, siguiendo aquí la idea de Carole Pateman. Así dicen que:

21 A. Gutmann y D. Thompson, Democracy and disagreement. Harvard: Harvard University Press. 1996, p. 143. 
A menos que los ciudadanos tengan la experiencia de razonar juntos en otras instituciones en las cuales gastan mucho de su tiempo, ellos no tendrán la posibilidad de desarrollar el interés o la habilidad que les permita deliberar efectivamente en política. ${ }^{22}$

Y justamente después, identifican esos otros ámbitos como los medios de comunicación, las organizaciones de cuidado médico, los grupos de interés, las asociaciones profesionales o las corporaciones; es decir, los elementos que componen la sociedad civil. ${ }^{23}$ Pero es en su obra posterior, Why deliberative democracy? donde de una forma más clara se refleja la influencia de Rawls en su planteamiento sobre la sociedad civil. Aquí también reiteran la idea de que:

Las teorías deliberativas buscan estructurar la sociedad civil parar equipar mejores ciudadanos para deliberar en la política [...] Sin una sociedad civil que proporciona el espacio de ensayo para la deliberación política, los ciudadanos tienen menos probabilidad de ser políticamente efectivos. ${ }^{24}$

Este último texto citado resulta revelador, ya que refleja cómo Gutmann y Thompson siguen presos de la dicotomía rawlsiana entre razón pública, o si se quiere, ámbito político, y sociedad civil. También para estos autores la sociedad civil no es en sí misma pública. Hay así dos procesos deliberativos diferenciados: el de la política y el del ámbito del trabajo o el de los grupos voluntarios en los que se participa. La diferencia con el proyecto rawlsiano está en que Gutmann y Thompson conciben la deliberación en la sociedad civil como un entrenamiento para participar adecuadamente en el foro público. Sólo si se participa deliberativamente en la sociedad civil (y se recibe una adecuada formación en la escuela) se estará contribuyendo a que la política pueda ser también deliberativa. Con esta idea están siguiendo la estela de los denominados defensores de «Argumento de la sociedad civil», el cual tiene su raíz en Tocqueville y también en Carole Pateman. ${ }^{25}$

Volviendo a la separación entre las esferas pública y privada, podemos observar que Gutmann y Thompson llegan a identificar la «política deliberativa»

22 Ibid., p. 359.

23 Es más, en concreto citan también en ese mismo párrafo el ámbito del trabajo, lo cual ayuda a enfatizar la idea de que para ellos la sociedad civil es el conjunto de la vida privada de los ciudadanos.

24 A. Gutmann y D. Thompson, Why deliberative democracy?, op. cit., p. 35.

25 C. Pateman, Participation and democratic theory. Cambridge: Cambridge University Press, 1970, p. 46. El argumento de la sociedad civil entiende que una sociedad civil fuerte (entendida como el ámbito privado) es el mejor modo de fortalecer también la vida democrática (el ámbito público). 
con el ámbito de la política ordinaria, mientras que la sociedad civil la identifican con las asociaciones y colectivos como iglesias y sinagogas o universidades, las cuales para estos autores no tienen efectos públicos, en concreto, no afecta a las libertades y oportunidades básicas de los ciudadanos. Esta es sin duda una idea más que discutible, ya que es obvio que las iglesias y universidades tienen efectos públicos, y es esto precisamente los que las convierte en miembros del foro público. Por todo ello, hemos de concluir que el enfoque de Gutmann y Thompson por lo que respecta al concepto de sociedad civil hereda los errores del rawlsiano, lo cual impide a estos autores percibir el verdadero alcance que adquiere la sociedad civil en nuestros días y que afortunadamente será reconocido por otros autores de la democracia deliberativa a los que aludiré a continuación.

\section{LA SOCIEDAD CIVIL COMO PARTE DE LA ESFERA PÚBLICA}

Dejando a un lado el errático enfoque rawlsiano, del que beben Gutmann y Thompson, y partiendo del giro que asienta la esfera pública en la sociedad civil, y al que antes hice alusión, los planteamientos del resto de autores son dos. Por un lado, los que quieren hacer a la sociedad civil una caja de resonancia de los intereses de los ciudadanos pero sin llegar a ejercer el poder directamente; y por otro, los que, yendo más allá, quieren hacer de ella un elemento de cambio institucional.

En el primer grupo encontramos a Habermas y a Seyla Benhabib. Para Habermas, la sociedad civil se compone por asociaciones que representan grupos de interés, partidos políticos, sociedades culturales, «grupos de interés público», interesados por fines como la defensa del medio ambiente, las iglesias y las asociaciones benéficas. Tales grupos, miembros del denominado por Habermas «mundo de la vida», se diferencian claramente de los ámbitos estatal y económico. Éstos últimos se guían por el poder, en el primero y el interés en el caso del mercado, sometidos ambos a la racionalidad estratégica. Sin embargo, los miembros de la sociedad civil se guían por la racionalidad comunicativa y se caracterizan por tejer relaciones de solidaridad y por la consecución de intereses universalizables y no unos meramente egoístas. Estos elementos nos revelan precisamente cuál es la función que Habermas encomienda a los grupos de la sociedad civil. El objetivo de tales grupos es, como he dicho, hacerse eco de los problemas sociales para hacerlos llegar a las instituciones y lograr con ello que sean tratados en el Parlamento. Es en la relación entre la sociedad civil y los procesos formales de toma de decisiones donde Habermas y Benhabib ubican la esfera pública. ${ }^{26}$ 
Ahora bien, la labor de estas asociaciones sólo puede entenderse si la ligamos a otra, la de opinión pública. Estas asociaciones que forman la sociedad civil para Habermas no son en realidad sino un sustituto de los ciudadanos privados, intelectuales y burgueses que en la época de la Ilustración reclamaban una exigencia de racionalidad a la acción pública. Se trataba aquí de ciudadanos privados que, sin embargo, mantenían discusiones públicas al realizar exigencias de una legitimación raciocinante de su actuación. Es esta exigencia de racionalización la que convierte a las reuniones de personas privadas en un baluarte mismo de la publicidad. Con esto, el esquema de la escisión entre lo público y lo privado quedó trastocado. Ahora, para empezar, la publicidad, o mejor dicho, la esfera pública, se alberga de una forma plena en el ámbito privado, mediante esas discusiones entre los ciudadanos pudientes, frente a la concepción de los teóricos del contrato que reducía lo público a lo estatal. Del mismo modo, la idea clave es que esos ciudadanos realizan exigencias de legitimidad racional al poder público y son creadores de una opinión pública fruto de la deliberación entre ellos, opinión que debe recibir la atención debida de las instituciones. ${ }^{27}$ Desde entonces, la manera más eficaz de influir en el poder político es a través de la opinión pública.

Sin embargo, esta forma de reclamar legitimidad racional desde la esfera pública sufrió un cambio en la época actual. En nuestros días, el papel desempeñado por aquellos ciudadanos privados será ocupado por las asociaciones, partidos, iglesias y grupos de interés, y ello (en cierta medida) con la ayuda inestimable de los medios de comunicación. ${ }^{28}$ Esas asociaciones, en el marco comunicativo de la sociedad civil identifican y recogen los problemas que se generan en el mundo de la vida y que tienen consecuencias relevantes para el funcionamiento del sistema. Por otro lado, articulan y tematizan de forma convincente tales intereses y necesidades y se hacen eco de ellos de una forma influyente ante las instituciones para reclamar y tratar de conseguir la solución de los mismos por el complejo parlamentario. A esto denomina Habermas la capacidad de problematización. Aquí el punto fundamental es que la sociedad civil ejerza una clara influencia sobre el ámbito político, ya que formando una opinión pública en buena medida marcará la agenda de las instituciones, forzando el apoyo a determinadas políticas y el rechazo de otras. En el espacio de la opinión pública se forma influencia y en él se lucha por ejercer influencia, ya que el poder administrativo requiere, en una democracia, acudir al mundo de la vida para validar sus decisiones, lo que le pone frente al problema de tener que considerar en algún grado las influencias que surgen de la sociedad civil. En

27 J. Habermas, Historia y crítica de la opinión pública. La transformación estructural de la esfera pública. Barcelona: G-Gili, 2002, pp. 129-30.

28 Ibid., p. 204. 
tercer lugar, la sociedad civil tiene como misión superar y eliminar las barreras y manipulaciones que afectan y distorsionan el espacio público. Finalmente, la sociedad civil también ejerce de instancia crítica de las decisiones tomadas en el proceso institucional, controlando el tratamiento que se hace de los temas dentro del sistema político.

Es esto lo que define a la política deliberativa, según nos dice Habermas en Facticidad y validez: el entrelazamiento existente entre dos subsistemas diferenciados y que caracteriza la esfera pública; por un lado, el político, encargado de la formación de la voluntad mediante toma de decisiones colectivamente vinculantes en los marcos formales institucionales; y por otro la estructura comunicativa de la opinión pública, basada en la sociedad civil, que actúa como una caja de resonancia de los problemas sociales y estimula la opinión. ${ }^{29}$

Finalmente, de esta relación que existe entre el subsistema político y el de la sociedad civil se deriva un hecho fundamental: la sociedad civil no actúa políticamente; sólo influye en el poder administrativo para dirigirlo en una determinada dirección, además de ejercer de esfera crítica a las decisiones tomadas. Tienen por ello ambos subsistemas funciones bien diferenciadas. Esto hace que no se dé una participación directa de los ciudadanos, y mucho menos de los grupos que forman la sociedad civil, en el foro público más allá de las formas establecidas como las elecciones. El encargado de la toma de decisiones es propiamente el subsistema político mediante las deliberaciones en el Parlamento, a la luz, eso sí, de la influencia ejercida por los grupos sociales de la sociedad civil.

Seyla Benhabib mantiene una visión cercana a Habermas y dibuja una sociedad civil como caja de resonancia de los problemas sociales, mientras que la toma de decisiones se mantiene en el plano institucional. ${ }^{30}$ Sin embargo, otros como Barber, Cohen y Rogers, Dryzek o Bohman han defendido una relación más dinámica entre los dos elementos de la esfera pública, de modo que la sociedad civil pueda intervenir en el proceso de decisiones. Con ello se pretende un reforzamiento de la sociedad civil para que no sea ésta un mero actor pasivo del proceso de toma de decisiones, y adquiera así un papel decisivo.

John Dryzek, aunque se mantiene en la órbita habermasiana, entiende que la labor de la sociedad civil debe ser, por un lado, la crítica al Estado, y por otro, la de convertirse en un mecanismo para resolver problemas. Ha de ser una entidad «paragubernativa». Así, señala como grupos de la sociedad civil a los movimientos ecologistas y su labor contra los desmanes de los Estados sobre el medio ambiente o los pacifistas y sus acciones contra los conflictos armados. Se trata, por ello, de grupos caracterizados por su oposición a los excesos del

29 J. Habermas, Facticidad y validez. Madrid: Trotta, 1998, p. 376.

30 S. Benhabib, loc. cit., pp. 67-94. 
Estado sometido al sistema capitalista. ${ }^{31}$ La influencia de la sociedad civil en el ámbito político puede ir desde actividades puntuales pero efectivas, como los boicots, hasta el mismo cambio cultural. ${ }^{32}$ Sirva de ejemplo la influencia del movimiento feminista para lograr el voto femenino o el divorcio y lo que ello supuso en las sociedades occidentales. Por ello, el papel de la sociedad civil no debe entenderse como meramente pasivo, a la expectativa de las decisiones institucionales, sino que es plenamente activo, no sólo para la misma constitución del poder político (mediante las elecciones), sino también como impulsora del cambio cultural y opositora al sistema político actual. A pesar de ello, la función de los grupos de la sociedad civil es la misma que la otorgada por Habermas, la resolución de los problemas apelando a intereses generalizables.

Bohman defiende una concepción de la sociedad civil similar a la habermasiana, aunque pretende desmarcarse de ésta en algunos aspectos. Para Habermas la esfera pública ocupaba el ámbito de relación entre el sistema institucional y la sociedad civil, mientras ésta estaba constituida por el conjunto de asociaciones voluntarias y las redes comunicativas tejidas entre ellas. Dichas asociaciones eran las encargadas que hacerse eco de los problemas sociales y presentarlos al marco institucional para que éste procurase su resolución. ${ }^{33}$ Pero Bohman trastoca esta relación, separando en dos niveles diferentes la sociedad civil y la esfera pública. La sociedad civil es más bien para Bohman la interacción de grupos para hacer organizaciones que les permitan participar en la esfera pública. De esta manera distingue entre los grupos que constituyen la sociedad civil de aquellos que propiamente intervienen en la esfera pública. La sociedad civil, como el agregado de redes y movimientos informales no son propiamente parte de la esfera pública. ${ }^{34}$ Ésta quedaría formada propiamente sólo por aquellos movimientos sociales que han adquirido un mayor reconocimiento, poder e influencia en nuestra sociedad y que son que realmente pueden influir en el ámbito político para hacer valer sus exigencias. Así cita por ejemplo los movimientos de derechos civiles y los feministas. Estos grupos pueden surgir de asociaciones y colectivos particulares de la sociedad civil pero mediante una fuerte organización logran ir más allá y pasar los hace actores colectivos con

31 J. Dryzek, Discursive democracy. Politics, policy and political science. Cambridge: Cambridge University Press, 2000 pp. 49, 89. La tesis de la dependencia del Estado moderno del éxito del sistema capitalista ha sido defendida por Claus Offe en su obra Contradictions of the Welfare State, de 1984. Para este autor, dicha dependencia tiene como límite infranqueable los recursos naturales. Cuando la devastación capitalista acabe con dichos recursos, el Estado del bienestar sellará su defunción.

32 J. Dryzek, Deliberative democracy and beyond. Oxford: Oxford University Press, 2000, p. 102.

33 J. Habermas, Facticidad y validez. op. cit., p. 436.

34 J. Bohman, Public deliberation. Massachusetts: The MIT Press, 1996, pp. 135-6. 
una voz unificada para hacerse oír en la esfera pública por razones públicas. Una vez reconocido su poder de expresión pública, son hechos parte de la agenda política. Esta orientación a lo público y la fuerte organización y relevancia social son lo que diferencia a estos grupos de otros que quedarán escorados en la sociedad civil. De esto es justo de lo que se trata, de que los grupos y asociaciones puedan organizarse y recabar el apoyo necesario para hacerse oír de una forma unificada en la esfera pública. Sólo así podrán influir de una forma efectiva sobre el ámbito institucional y lograr los objetivos propuestos.

Esta distinción de Bohman parece razonable. Es cierto que en la sociedad civil podemos encontrar muchas asociaciones y colectivos que recogen las necesidades y exigencias de grupos sociales. Pero también es verdad que sólo una parte de ellos logran hacer oír su voz en la esfera pública, mientras que el resto desempeñan un papel de algún modo episódico más allá de las redes sociales de los que surgieron. Bohman pone el caso de los movimientos pro-vida. Éstos, según él no son parte de la esfera pública porque no han alcanzado una mayor resonancia y formas de expresión más allá de las iglesias de donde salieron, aunque puedan resultar convincentes sus argumentos a un sector de la sociedad.

Pero la crítica fundamental a Habermas aparece en la relación establecida por Bohman entre los públicos y las instituciones. Bohman criticará la escisión tajante propia de Habermas entre la esfera de la formación de la opinión, la esfera pública, y la de la voluntad, el ámbito político, así como que dicha relación sea meramente unidireccional, de simple influencia del espacio público informal sobre el ámbito institucional. Para Bohman esa relación debe entenderse en un sentido más dinámico. Esto se debe a la importancia que Bohman otorga a la complejidad presente en nuestras sociedades. Los movimientos sociales hacen que surjan nuevos públicos que influyen en los discursos políticos de varias formas: introducen nuevos temas, focalizan la atención en los problemas y ofrecen nuevas interpretaciones. Pero además, los nuevos públicos pueden incluso llegar a transformar las instituciones democráticas y los marcos de deliberación para hacerlos más participativos. Así hay una dialéctica en la democracia: tan pronto como las instituciones se estabilizan son transformadas por los públicos que son dejados fuera. ${ }^{35}$ Por ese motivo, las instituciones deben, en definitiva, estar abiertas a la deliberación pública. Las instituciones deben convertirse en una esfera pública política, de tal forma que el gobierno descanse en la misma opinión pública. Esto pasa por crear nuevos foros y reformar instituciones en las que los ciudadanos deliberen y hagan un uso público de su razón de nuevas formas. Es un fin indispensable para la sociedad pluralista el incrementar el ámbito de participación democrática con lo que poder hacer frente a los retos de la complejidad social y el pluralismo de valores. 
Finalmente, otros autores han ido más allá y hablan directamente de la cooperación entre el Estado y la sociedad civil para la resolución de los problemas políticos. Por un lado, Barber, con su proyecto descentralizador de la «Democracia fuerte» propone que esa descentralización no suponga que el Estado abjure de sus responsabilidades delegándolas en el mercado, como pretenden los defensores del Estado mínimo. Más bien, que se produzca una cooperación entre el Estado y la sociedad civil para la gestión de los asuntos públicos, gracias al compromiso cívico de los ciudadanos. ${ }^{36}$

Por último, Joshua Cohen y Joel Rogers otorgan una serie de funciones a los grupos de la sociedad civil que van también más allá de las asignadas por Habermas: Por un lado, la información. Al igual que en el esquema habermasiano, para Cohen y Rogers, los grupos pueden informar a los políticos sobre las preferencias o necesidades de los ciudadanos y sobre el impacto de la legislación sobre los mismos, lo cual permite al aparato estatal una mejor elección de los medios para su solución. En segundo lugar, dado que las desigualdades materiales se traducen en desigualdades políticas, los grupos pueden contribuir a paliar éstas mediante la mancomunación de bienes de los más necesitados y la representación de los intereses peor organizados. En tercer lugar, las asociaciones pueden funcionar como «escuelas de democracia». Mediante la participación en tales grupos los ciudadanos pueden adquirir competencia cívica para una participación más efectiva en el foro público, que para Cohen y Rogers tendrá un carácter deliberativo. ${ }^{37}$ Finalmente, y como punto clave, las asociaciones pueden ser depositarias de unas funciones de gobierno que les permitan resolver de una forma más efectiva los problemas ciudadanos. Esto puede suceder allí donde las asociaciones resulten más competentes que las autoridades publicas para la gestión y solución de los problemas. Como dicen estos autores: «Ayudan a formular y ejecutar las políticas públicas que suplementan o suplantan las acciones más directamente regulativas del Estado». ${ }^{38}$ Las funciones de los grupos dependen de su configuración y pueden ir desde el control de la ejecución estatal de las políticas, o la comunicación de los problemas a los cuerpos legislativos hasta el suministro de servicios sociales.

No obstante, también es cierto, como nos recuerdan, que esta cesión de

36 B. Barber, Un lugar para todos. op. cit., p. 69.

37 La influencia de Tocqueville y de Carole Pateman se hace aquí notoria. No obstante, Cohen y Rogers insisten en desligar su idea de la democracia asociativa de la propuesta de Carole Pateman de la democracia en el lugar de trabajo, ya que los primeros son escépticos con la posibilidad de que las empresas generen una forma de estructuración democrática dentro de las mismas, debido a la heterogeneidad de intereses que estos autores encuentran dentro de las empresas actuales.

38 J. Cohen y J. Rogers, «Asociaciones secundarias y gobierno democrático», Zona abierta, 84/85, (1998), p. 57. 
funciones de gobierno más directas a las asociaciones no supone que la democracia asociativa pretenda transformar la estructura del poder político en otra diferente. Más bien consiste en una estrategia de reforma de ciertos aspectos de la práctica política habitual. En todo caso, vemos cómo estos autores dan un paso más allá de la teoría habermasiana y apuestan por una descentralización política que haga a las asociaciones de la sociedad civil mantener una relación más estrecha con el engranaje institucional hasta el punto de compartir sus funciones de gobierno.

\section{CONCLUSIÓN}

Hecho este análisis sobre el papel otorgado a la sociedad civil en el marco de la democracia deliberativa, podemos decir que existe una línea evolutiva continua que enlaza los planteamientos de los distintos autores y que camina en dirección al reforzamiento de la sociedad civil. Comenzamos con Rawls, el cual se mantenía fiel a la escisión clásica entre los ámbitos público y privado, esto es, de lo político y la sociedad civil, tal como se gestó en la Modernidad y se transmitió a través de la sociedad civil burguesa teorizada por Hegel. En este primer estadio, lo público es asimilado a lo estatal, mientras que la sociedad civil queda más bien como un ámbito privado compuesto por las razones no públicas, sin ninguna influencia en lo público.

En un segundo nivel nos encontramos a Gutmann y Thompson. En ellos persiste la distinción clásica de los ámbitos público y privado, pero a diferencia de Rawls, ya se afirma una cierta relación entre lo político y la sociedad civil. Ésta se convierte en una especie de preparación para fomentar una esfera política mejor. Es decir, si la sociedad civil se rige por la deliberación moral y permite el cultivo de las virtudes cooperativas, se podrá alcanzar una esfera pública también deliberativa que vaya más allá del sistema antagonista del regateo que ha imperado en la cultura liberal. La democracia deliberativa será posible a través de una sociedad civil también deliberativa.

En tercer lugar podemos situar el enfoque habermasiano seguido por Seyla Benhabib. Para ellos el foro público ya no se restringe a la acción estatal, sino que se amplia para dar cabida también a la sociedad civil. Pero las diferencias no acaban aquí. Ahora el concepto de sociedad civil sufre una transformación: ya no hace referencia al conjunto de las esferas de la vida priva de las personas, como las asociaciones voluntarias en las que colabora, la familia o el trabajo, sino más bien a aquellas asociaciones y grupos voluntarios que actúan como caja de resonancia de los problemas que afectan a los ciudadanos e intentan hacerlos llegar a la esfera institucional. Tales grupos buscan influir en ese ámbito institucional para alcanzar la solución a esos problemas, pero sin intervenir 
directamente en el proceso de toma de decisiones.

Finalmente, en un último escalón encontramos a aquellos autores que, como Dryzek, Bohaman, Barber y Cohen y Rogers, no se limitan a defender una sociedad civil que «asedie» a la esfera institucional sin entrar en la toma de decisiones al modo de Habermas, sino que apuestan por otra que colabore con el poder institucional en la resolución de los problemas. De este modo, el giro respecto al planteamiento rawlsiano es total. Se pasa de una sociedad civil ajena a la esfera pública a otra completamente volcada en la acción política, hasta el punto de liderar, como en el caso de Bohman, la reforma institucional hacia unos modelos más participativos.

Esta evolución del concepto de sociedad civil en la democracia deliberativa, es una muestra de cómo desde esta teoría de la democracia se han podido atisbar los cambios producidos en el ámbito público de las sociedades democráticas en las últimas décadas. Tales cambios no hacen sino reflejar la apuesta de la democracia deliberativa por dar el protagonismo a los ciudadanos en la esfera pública. Ciertamente, no se pretende una participación directa de los ciudadanos en los procesos de toma de decisiones, ya que ello en nuestras sociedades es inviable, pero sí que se intenta que la acción política no quede en manos de los políticos, sino que los grupos de la sociedad civil desempeñen un papel lo más relevante posible como miembros del foro público. Éste ya no queda reducido a los representantes, sino que debe hacer un hueco a los colectivos en los cuales el conjunto de ciudadanos participa de una forma más o menos directa. Con ello el principio republicano de autogobierno podrá ser alcanzado en el marco de nuestras sociedades complejas.

Pedro Jesús Pérez Zafrilla es doctorando en Filosofía y Becario de Investigación FPU del Ministerio de Educación y Ciencia en el Departamento de Filosofía del Derecho, Moral y Política, Facultad de Filosofía y Ciencias de la Educación de la Universidad de Valencia

\section{Publicaciones recientes:}

«Los límites de la posición original en la obra de John Rawls», en Estudios filosóficos, núm 164, 2008.

«El nacionalismo rumano en la obra de Mircea Eliade», en Thémata, núm. 39. 2007.

\section{Líneas de investigación:}

Filosofía política, teorías de la democracia, democracia deliberativa, liberalismo, multiculturalidad, secularización.

Dirección postal:

Av. Blasco Ibáñez 30, 46010 Valencia.

Dirección electrónica: P.Jesus.Perez@uv.es 